\title{
Occupational mortality among women in England and Wales
}

\author{
EVE ROMAN, VALERIE BERAL, HAZEL INSKIP
}

\begin{abstract}
Occupational mortality in women who died in England and Wales from 1970 to 1972 was analysed. Many of the associations found were consistent with those that have been described for men, with high mortality ratios for cirrhosis in barmaids and publicans, for suicide in the medical and allied professions, and for respiratory disease in textile workers. Parity is a determinant of patterns of disease in working women, and the relative excess of cancer of the breast, ovary, and uterine body in professional and clerical workers probably reflected the high proportion of nulliparous women in these groups. Other associations may have reflected true occupational hazards; one observation requiring further attention was the high proportional mortality ratio for anaemia in textile and clothing workers.

The description of the occupational mortality among women in England and Wales is hampered by the incomplete recording of information about women's occupations at registration of death. As women now constitute $40 \%$ of the workforce, often have their own specific occupations, and possibly also have their own diseases related to specific occupations it is time for the registrar's guidelines on the recording of women's occupationlast reviewed at the beginning of this century-to be revised.
\end{abstract}

\section{Introduction}

In England and Wales the Registrar General's decennial supplements on mortality and occupation have traditionally described the patterns of disease of most women-that is, those currently or previously married - in terms of their husband's occupation. ${ }^{1.3}$ The relation between women's own occupation and mortality has received comparatively little attention because information about married women's occupation is rarely requested at registration of death and the number of single women whose occupation is recorded is fairly small. ${ }^{+5}$ The Office of Population Censuses and Surveys first produced tables relating the mortality of all women, regardless of marital state, to their own occupation for the period 1970-2. Although some of the findings were published, social rather than occupational differentials were emphasised. ${ }^{6} \mathrm{~A}$ comprehensive summary of these occupational data was subsequently compiled and published, ${ }^{7}$ and some of the main findings for women aged 15-74 are reviewed here.

\footnotetext{
Epidemiological Monitoring Unit, London School of Hygiene and Tropical Medicine, London WC1E 7HT

EVE ROMAN, PHD, research fellow

VALERIE BERAL, MRCP, senior lecturer

HAZEL INSKIP, MSC, research fellow

Correspondence to: Dr Roman.
}

\author{
Data and methods
}

An occupation was recorded for 73394 (21\%) of the 354845 women aged 15-74 who died during 1970-2. ${ }^{6}$ The 63193 women assigned to one of the $222{ }^{\circ}$ occupational units described by the Registrar General ${ }^{8}$ formed the basis of these analyses. Cause of death was classified using the 8 th revision of the International Classification of Diseases. ${ }^{9}$ For each occupational unit the $\mathcal{G}$ numbers of deaths and age standardised proportional mortality ratios by.cause for the age groups 15-64 and 65-74 were available from unpublished tables held at the Office of Population Censuses and Surveys, deaths of all women in 1970-2 having been used as the reference group. Age standardised $\vec{P}$ proportional mortality ratios for specific causes in women aged 15-74 were calculated from these data. The significance of all proportional mortalityo ratios was tested using the method described by Bailar and Ederer. ${ }^{110} \supset$ Proportional mortality ratios in women aged $15-64,65-74$, and $15-74$ that were significantly greater than $100(p<0.05)$ were extracted and reported $\subseteq$ with a fuller description of the methods used. ${ }^{7}$ The aim of that report was to summarise and make available information on occupational mortality in $\vec{\bullet}$ women for others to use and interpret. No discussion of the findings waso् included.

\section{Results}

One hundred and thirty nine $(63 \%)$ of the 222 occupational units\% examined had at least one significantly raised mortality ratio among the 730 causes of death examined. There were 317 significantly high proportional $\overrightarrow{0}$ mortality ratios in the age group 15-74. Tables I-IV show the proportional3 mortality ratios for certain selected causes of death. Five occupational units? had significantly raised proportional mortality ratios for cirrhosis of theo liver, and two of these groups, publicans and barmaids, worked in close contact with alcohol (table I). Table II lists the 11 occupational units with high proportional mortality ratios for suicide; three of these units belonged

TABLE I-Mortality from cirrhosis of the liver (ICD 571) among women aged 15-74 in England and Wales in 1970-2: significantly high proportional mortality ratios $(p<0.05)$

\begin{tabular}{lc}
\hline Occupation (unit No) & $\begin{array}{c}\text { Proportional mortality ratio } \\
\text { (No of deaths) }\end{array}$ \\
\hline Telegraph and radio operators (128) & $1152(3)^{\star}$ \\
Senior government officials (173) & $761(3)$ \\
Saleswomen, valuers, estate agents, etc (150) & $610(4)^{\star}$ \\
Publicans, innkeepers, etc (154) & $490(5)^{\star}$ \\
Barmaids, etc (155) & $439(8)^{\star}$ \\
\hline${ }^{\star} \mathrm{p}<0.01$. &
\end{tabular}
TABLE II-Mortality from suicide (ICD E950-959) among women aged 15-74 in England
and Wales in 1970-2: significantly high proportional mortality ratios $(p<0.05)$

\begin{tabular}{lcl}
\hline Occupation (unit No) & $\begin{array}{c}\text { Proportional mortality ratio } \\
\text { (No of deaths) }\end{array}$ \\
\hline Medical practitioners (181) & $589(15)^{\star}$ \\
Draughtswomen (218) & $522(7)^{\star}$ \\
Authors (206) & $496(9)^{\star}$ \\
Physiotherapists (188) & $493(4)$ \\
Nurses (183) & $255(148)^{\star}$ \\
Managerst (180) & $208(11)$ \\
Labourers and unskilled workerst (114) & $200(33)^{\star}$ \\
Domestic housekeepers (158) & $174(37)^{\star}$ \\
Typolteachers (193) & $140(52)$ \\
Clerks, secretaries, etc (141) & $138(105)^{\star}$
\end{tabular}

${ }^{*}<0 \cdot 01$.
†Not elsewhere classified 
to the medical and allied professions-namely, doctors, nurses, and physiotherapists.

High mortality ratios for respiratory diseases were found in women working in the textile industry; of the 13 occupational units with significantly high proportional mortality ratios for all respiratory diseases, six were connected with the manufacture of textiles (table III). Table III also shows the proportional mortality ratios for specific respiratory conditions and lung cancer. The high proportional mortality ratios for all respiratory diseases in textile workers were mainly due to raised mortality from bronchitis and emphysema. Mortality from pneumoconiosis, which includes the disease related to cotton dust, byssinosis, was significantly high in winders and reelers. Most of the proportional mortality ratios for lung cancer in textile workers were below 100, that in weavers being significantly reduced (table III). In contrast to textile workers, the other occupations with high proportional mortality ratios for all respiratory diseases tended to have high ratios for all three of these cancer sites were often found in the same occupation. Table IV lists the five occupations with significantly high proportional mortality ratios for at least two of these three malignancies. In teachers and clerks the proportional mortality ratios for all three cancer sites were significantly high. A further 22 occupational units had significantly raised mortality from only one of these cancers (table V). Mortality from cancer of the uterine cervix (ICD 180) was not increased in occupational units with high proportional mortality ratios for cancers of the breast, ovary, and uterine body. Only two occupational groups had significantly high proportional mortality ratios for cervical cancer: spinners, doublers, and twisters (occupational unit 65) had a proportional mortality ratio of 200 (14 deaths), and machine tool setters (occupational unit 38) had a proportional mortality ratio of 386 (four deaths).

Diseases of the circulatory system exhibited a surprising lack of variation between occupations. Only one group, office machine operators (occu-

TABLE III-Mortality from respiratory disease (ICD 460-519) and lung cancer(ICD I62) among women aged 15-74 in England and Wales in 1970-2

\begin{tabular}{|c|c|c|c|c|c|c|}
\hline \multirow[b]{2}{*}{ Occupation (unit No) } & \multicolumn{6}{|c|}{ Proportional mortality ratio (No of deaths) } \\
\hline & $\begin{array}{l}\text { All respiratory diseases } \\
\text { (ICD 460-519) }\end{array}$ & $\begin{array}{c}\text { Pneumonia } \\
\text { (ICD 480-486) }\end{array}$ & $\begin{array}{l}\text { Bronchitis, emphysema } \\
\text { (ICD 490-422) }\end{array}$ & $\begin{array}{l}\text { Asthma } \\
\text { (ICD 493) }\end{array}$ & $\begin{array}{l}\text { Pneumoconiosis } \\
\text { including byssinosis } \\
\text { (ICD 515-516) }\end{array}$ & $\begin{array}{l}\text { Lung cancer } \\
\text { (ICD 162) }\end{array}$ \\
\hline \multicolumn{7}{|l|}{ Textile workers: } \\
\hline Fibre preparers (64) & $181(62)^{\star}$ & $162(29) \dagger$ & $205(22)^{\star}$ & $323(2)$ & & $59(7)$ \\
\hline Spinners (65) & $157(73)^{\star}$ & $174(41)^{\star}$ & $164(24) \dagger$ & $78(1)$ & & $107(19)$ \\
\hline Textile processorsł $(73)$ & $157(34) t$ & $186(20) \dagger$ & $154(10)$ & & $3205(1)$ & $34(3)$ \\
\hline Textile labourers $\ddagger$ (110) & $146(64)^{\star}$ & $121(27)$ & $204(28)^{\star}$ & $99(2)$ & 3374 (1) & $55(9)$ \\
\hline Winders, reelers, etc (66) & $142(71)^{\star}$ & $153(39) \dagger$ & $146(21)$ & $88(2)$ & $3029(2)^{\star}$ & $59(11)$ \\
\hline Weavers $(68)$ & $123(187)^{\star}$ & $118(96)$ & $137(64) \dagger$ & $103(2)$ & $1806(1)$ & $71(34) \dagger$ \\
\hline \multicolumn{7}{|l|}{ Non-textile workers: } \\
\hline Ceramic formers (13) & $233(19)^{\star}$ & $154(6)$ & $128(3)$ & $725(4)^{\star}$ & $26853(3)^{\star}$ & $65(2)$ \\
\hline Printing press operators ( 86 ) & $168(21) \dagger$ & $255(16)^{\star}$ & $24(1)$ & 159 (i) & & $77(4)$ \\
\hline Engineering labourers $\ddagger$ (108) & $160(33) \dagger$ & $171(17)$ & $95(6)$ & $205(2)$ & & $94(8)$ \\
\hline Maids and related (164) & $129(535)^{\star}$ & $152(319)^{\star}$ & $92(111)$ & $78(15)$ & $185(1)$ & $93(143)$ \\
\hline Launderers, etc (168) & $124(103) \dagger$ & $152(63)^{\star}$ & $129(9)$ & $47(2)$ & & $113(36)$ \\
\hline Charwomen and cleaners (166) & $121(216)^{\star}$ & $130(114) \dagger$ & $129(70) \dagger$ & $45(4)$ & & $134(102)^{\star}$ \\
\hline Tailorsł $(74)$ & $120(147) \dagger$ & $141(90)^{\star}$ & $65(29) \dagger$ & $160(8)$ & & $94(40)$ \\
\hline
\end{tabular}

mortality from pneumonia but not from bronchitis and emphysema (table III). Printing press operators, tailors, and women in the three occupations associated with cleaning - namely, maids, launderers, and charwomenhad high proportional mortality ratios for pneumonia, whereas only charwomen had a significantly high proportional mortality ratio for bronchitis and emphysema. Women working as ceramic formers had significantly high mortality ratios from asthma and pneumoconiosis.

Cancers of the breast, ovary, and body of the uterus were more common in several clerical and professional groups, and high proportional mortality

TABLE IV-Mortality from cancer of breast, ovary, and uterine body among women aged 15-74 in England and Wales in 1970-2: units with significantly raised proportional mortality ratio for at least two of these cancer sites

\begin{tabular}{lccc}
\hline & \multicolumn{3}{c}{ Proportional mortality ratio (No of deaths) } \\
\cline { 2 - 4 } Occupation (unit No) & $\begin{array}{c}\text { Breast cancer } \\
\text { (ICD 174) }\end{array}$ & $\begin{array}{c}\text { Ovarian cancer } \\
\text { (ICD 183) }\end{array}$ & $\begin{array}{c}\text { Uterine cancer } \\
\text { (ICD 181, 182) }\end{array}$ \\
\hline Clerks and cashiers (139) & $132(806)^{\star}$ & $130(286)^{\star}$ & $132(91) \dagger$ \\
Typists, secretaries, etc (141) & $139(383)^{\star}$ & $140(136)^{\star}$ & $123(37)$ \\
Proprietors and management (sales) (143) & $120(203)^{\star}$ & $140(84)^{\star}$ & $99(22)$ \\
Schoolteachers (193) & $160(311)^{\star}$ & $177(123)^{\star}$ & $158(38)^{\star}$ \\
Teachers $¥$ (194) & $158(68)^{\star}$ & $182(28)^{\star}$ & $155(8)$
\end{tabular}

${ }^{\star} \mathrm{p}<0.01 . \quad \dagger 0.01<\mathrm{p}<0.05 . \ddagger$ Not elsewhere classified. pational unit 140), had significantly high mortality from ischaemic heart disease (ICD 410-414); and only three groups had significantly high mortality from cerebrovascular disease (ICD 430-438) - namely, processors of food (occupational unit 81), canteen assistants (occupational unit 161), and charwomen (occupational unit 166).

Mortality from anaemia (ICD 280-285) was high in makers of textile fabrics and related products (occupational unit 72 , proportional mortality ratio $=567, p<0.01$, based on six deaths), the only group with a significant increase in this condition at age 15-74 based on more than one death. Makers of clothing and related products (occupational unit 77) also had a high proportional mortality ratio for anaemia, which was significant at age 65-74 (proportional mortality ratio $=440, \mathrm{p}<0 \cdot 01$, based on four deaths).

\section{Discussion}

Many of the occupational associations described here are plausible and similar to those previously observed in men $^{6}$ - for example, the high mortality from cirrhosis of the liver in occupations with easy access to alcohol, from suicide in the medical professions with ready access to drugs, and from respiratory disease in the textile industry. The association between textile manufacturing and byssinosis, a disease related to cotton dust, is well documented.

TABLE $\mathrm{V}-$ Mortality from cancer of breast, ovary, and uterine body among women aged 15-74 in England and Wales in 1970-2: occupational units with significantly raised proportional mortality ratio $(p<0 \cdot 05)$ for only one of these sites of cancer

\begin{tabular}{|c|c|c|c|c|c|}
\hline \multicolumn{2}{|c|}{ Breast cancer (ICD 174) } & \multicolumn{2}{|c|}{ Ovarian cancer (ICD 183) } & \multicolumn{2}{|c|}{ Uterine cancer (ICD 181,182) } \\
\hline Occupation (unit No) & $\begin{array}{l}\text { Proportional mortality ratio } \\
\text { (No of deaths) }\end{array}$ & Occupation (unit No) & $\begin{array}{l}\text { Proportional mortality ratio } \\
\text { (No of deaths) }\end{array}$ & Occupation (unit No) & $\begin{array}{l}\text { Proportional mortality ratio } \\
\text { (No of deaths) }\end{array}$ \\
\hline University teachers (192) & $325(5)$ & Maintenance fitters ( 42 ) & $1334(2)$ & Paper product makers $(84)$ & $326(7)$ \\
\hline Commercial travellers (148) & $246(9)$ & Finance brokers (149) & $711(3)$ & Clergy (213) & $293(8)$ \\
\hline Social workers $(215)$ & $199(51)^{\star}$ & Woodworkers $\nmid$ (59) & $449(4)$ & Cutters and lasters (62) & $230(9)$ \\
\hline Mining managers $\uparrow(177)$ & $186(14)$ & Engineering managers (175) & $442(4)$ & Domestic housekeepers (158) & $155(33)$ \\
\hline Entertainers (207) & $175(19)$ & Valuers (180) & $327(11)^{\star}$ & & \\
\hline School housekeepers (157) & $163(39)^{\star}$ & Local authority officers (174) & $324(6)$ & & \\
\hline Managers $\dagger(180)$ & $148(41)$ & Laboratory assistants (219) & $244(8)$ & & \\
\hline Telephone operators (127) & $134(61)$ & Hoteliers (156) & $192(18)$ & & \\
\hline Nurses (183) & $115(288)$ & Shop saleswomen (144) & $124(109)$ & & \\
\hline
\end{tabular}

${ }^{\star} \mathrm{p}<0.01 . \quad \dagger$ Not elsewhere classified 
Although only five deaths were specifically attributed to this category of disease in textile workers, some of the deaths attributed to bronchitis, emphysema, asthma, and pneumonia may also have been related to byssinosis. It is unlikely that smoking could explain the excess mortality from respiratory disease in textile workers as mortality ratios for lung cancer were low in these occupations (table III).

Non-textile workers with high mortality from all respiratory diseases generally had high mortality ratios for pneumonia but not for bronchitis and emphysema or pneumoconiosis. The main exception was ceramic formers, who had significantly high proportional mortality ratios for asthma and pneumoconiosis, and this may reflect occupational exposures. Three of the remaining six occupational units with significantly high mortality from all respiratory disease were associated with cleaning, and a dusty work environment could have contributed to this excess. Other factors such as smoking may, however, be implicated as the proportional mortality ratio for lung cancer in one group, charwomen and cleaners, was significantly high (table III). Male cleaners (occupational unit 166) also had significantly high mortality from pneumonia and lung cancer. ${ }^{6}$

Selective factors determining whether a woman works and the type of work she does will in some cases be related to her risk of disease. For example, nulliparous women are more likely than multiparous women to work outside the home $\mathrm{e}^{11}$; and nulliparity is associated with an increased risk of cancer of the breast, ovary, and uterine body. ${ }^{1213}$ This relation probably explains why the proportional mortality ratios for certain cancers of the reproductive system are high and tend to cluster in occupational groups, such as teachers, that contain fairly large proportions of nulliparous women. ${ }^{11}$ Unlike other cancers of the reproductive system, cervical cancer is more common in multiparous women, ${ }^{12}{ }^{13}$ and this may explain why the proportional mortality ratio for this condition was significantly raised in only two occupational units. The surprising lack of occupational units with significantly high proportional mortality ratios for diseases of the circulatory system may also be because these conditions are associated with multiparity, ${ }^{14}$ is or because women with cardiovascular disorders may be less likely to work than other women.

The relations described here are only a selection of the findings in the report of the Office of Population Censuses and Surveys. Although several other associations can be identified, most must remain as hypotheses to be tested against other data. One observation deserving further investigation is the high mortality from anaemia in textile and clothing workers, especially as this is not the first time that such an association has been evident. In England and Wales high mortality from all haematological diseases was reported for men working in the clothing industry who died in $1970-2^{6}$ and men working in the textile industry who died in 1976-80. ${ }^{16}$ Furthermore, in the 1931 Registrar General's decennial supplement the standardised mortality ratios for all diseases of the blood and blood forming organs were 156 for male textile workers $(p<0.01$, based on 92 deaths) and 134 for single female textile workers $(p<0.05$, based on 61 deaths). ${ }^{1}$ It has been suggested that this association might reflect the side effects of drugs, such as phenylbutazone, used to treat rheumatoid arthritis, ${ }^{6}$ but as these drugs were not available in the 1930s an occupational explanation might be more likely.

Proportional mortality ratios for one condition may in theory be distorted by exceptionally high or low mortality from other conditions, but this potential bias has been shown to be of little practical importance for data on occupational mortality of the type analysed here. ${ }^{17}{ }^{18} \mathrm{It}$ is important to remember, however, that biases caused by the incomplete recording of women's occupation at registration of death could have affected the results; that some of the proportional mortality ratios could have been significantly high by chance, as a large number of tests were performed on these data; that the comparison was with the mortality among all women, not those with an occupation recorded at registration of death; and that many of the occupational units described in the 1970 classification contained few or no deaths of women, whereas others, such as clerical and service occupations, contained several thousand. Although these problems will still be present in the forthcoming decennial supplement on occupation and mortality, information will be available on about twice as many women as in 1970-2 as the data will cover four years instead of three and the proportion of women aged 15-64 with an occupation recorded at registration of death increased from $21 \%$ in $1970-2$ to $30 \%$ in $1979 .{ }^{5}$ Nevertheless, still only half of all economically active women have an occupationo recorded at registration of death. One reason for the under-report- $D$ ing of occupation at registration of death can be found in them guidelines to registrars, whose instructions include the following:

"For a married woman or widow the registrar is required to enter the deceased's occupation and the words 'wife (or widow) of ___ and the name and occupation of the husband. ... It is the aim of the registrar to record the latest full time occupation followed by the deceased . . . in the case of a woman who is not employed at the date of her death the last full time occupation should not [our italics] be recorded unless she haso been in paid employment for most of her life." 6

Hence for most married women their husband's occupation is $\overrightarrow{0}$ recorded and their own part time or previous full time occupation is: omitted. Although the husband's occupation may be a more reliable $\vec{\omega}$ indicator of a married woman's social and economic circumstances than her own occupation, it cannot be used in occupational analyses. 3 Moreover, women's participation in the labour force has increasedi since the registrar's guidelines on the recording of women's occupation were last revised at the beginning of this century. Women now make up more than $40 \%$ of the total labour force; theyo spend, on average, about two thirds of their potential working life in paid employment; and, although many leave the labour force when they have children, most return when family commitmentso permit. ${ }^{19-22}$ Unless the guidelines issued to registrars are modified, analyses relating women's occupations to disease will continue to suffer from the potential biases and difficulties associated with interpreting incomplete information.

We thank Michael McDowall and Michael Alderson, of the Office of Population Censuses and Surveys, for their help and advice; John Fox, of City University, and Mollie Newhouse, of the London School of Hygiene@ and Tropical Medicine, for their comments on a previous draft; and Helen Edwards for typing the manuscript.

\section{References}

1 Office of Population Censuses and Surveys. Occupational mortality: the Registrar General's decennio supplement part IIa 1931. London: HMSO, 1936.

2 Office of Population Censuses and Surveys. Occupational mortality: the Registrar General's decennia supplement part II 1951. London: HMSO, 1958.

3 Office of Population Censuses and Surveys. Occupational mortality: the Registrar General's decennia supplement 1961. London: HMSO, 1971.

4 Macfarlane A. Official statistics and women's health and illness. Equal Opportunities Commissio o-

Research Bulletin 1980;No 4 .
McDowall M. Measuring women's occupational mortality. Population Trends. London: HMSO 1983. (No 34.)

6 Office of Population Censuses and Surveys. Occupational mortality: the Registrar General's decennia supplement 1970-72. London: HMSO, 1978. (Series DS1.) 7 Office of Population Censuses and Surveys. Women's occupational mortality 1970-72. London음
HMSO, 1985. (Series DHI 85/1.)

8 Office of Population Censuses and Surveys. Classification of occupations. London: HMSO, 1970. ㅇ

9 World Health Organisation. Intemational statistical classification of diseases, injuries and causes of death. 8th revision conference, 1965. Geneva: WHO, 1967.

10 Bailar JC, Ederer F. Significance factors for the ratio of a Poisson variable to its expectation Biometrics 1964;20:639-47.

11 Martin J, Roberts C. Women and employment: a lifetime perspective. The report of the 1980 $D E / O P C S$ women and employment survey. London: HMSO, 1984.

12 Miller AB, Barclay TH, Choi NW, et al. A study of cancer, parity and age at first pregnancy. Chronic Dis 1980;33:595-605.

13 Beral V. Parity and susceptibility to cancer. In: Fetal antigens and cancer. London: Pitmane 1983:182. (Ciba Foundation Symposium No 96.)

14 Beard M, Faster V, Annegers J. Reproductive history in women with coronary heart disease. $A m$ Epidemiol 1984;120:108-14.

15 Beral V. Long term effect of child bearing on health. I Epidemiol Community Health (in press). T 16 Kirby P. Death in the textile industry. A proportional mortality study of 952 dyers, bleachers, and textil workers who died between 1976 and 1980. London: Transport and General Workers Union 1985.

17 McDowall M. Adjusting proportional mortality ratios for the influence of extraneous causes of death. Statistics in Medicine 1983;2:467-75.

18 Roman E, Beral V, Inskip H, McDowall M, Adelstein A. A comparison of standardized and proportional mortality ratios. Statistics in Medicine 1984;3:7.

19 Office of Population Censuses and Surveys. General household survey. London: HMSO, 1984 ก (No 12.)

20 Joshi $\mathrm{H}$. Women's participation in paid work: further analysis of the women and employment survey London: Department of Employment, 1984. (Research paper No 45.)

21 Office of Population Censuses and Surveys. Social trends. London: HMSO, 1984. (No 14.)

22 Bhrolchain MN. Paid work and the tempo of childbearing: longitudinal evidence. London: Centre for Population Studies, 1984. (Research paper No 84.)

(Accepted 4 April 1985) 